\title{
AMBIENTES VIRTUAIS DE APRENDIZAGEM: LIMITES E POSSIBILIDADES PARA UTILIZAÇÃO NO ENSINO MÉDIO
}

\author{
VIRTUAL LEARNING ENVIRONMENTS: LIMITS AND POSSIBILITIES FOR USE IN HIGH \\ SCHOOL
}

Claudinete de Jesus da Silva ${ }^{1}$

\author{
Submetido: 04/01/2021 \\ Aprovado: 21/01/2021
}

\begin{abstract}
RESUMO
Ambiente Virtual de Aprendizagem (AVA) é todo o espaço que veicula conteúdos por intermédio das mídias tecnológicas com as comunicações síncrona e assíncrona entre os participantes das modalidades à distância, também denominado de ciberespaço. Este artigo tem como objetivo reconhecer o AVA e seu conjunto de mídias como objeto dialógico na sala de aula, discutindo formações ao docente, qual é um dos grandes desafios para o manuseio de recursos tecnológicos, principalmente no que tange a proposta do ambiente virtual por intermédio da Educação a Distância $(\mathrm{EaD})$ como mediação no processo de ensino e aprendizagem no ensino médio. $O$ estudo se refere a uma pesquisa do tipo bibliográfica descritiva com abordagem qualitativa. As mudanças educativas exigem do educador uma nova postura e é de sua competência ter fluência digital e dominar com eficiência as novas ferramentas digitais educacionais adquirindo uma prática pedagógica inovadora dinamizando a aprendizagem e colaborando na construção de cidadãos críticos e reflexivos através de formações pedagógico-tecnológicas contínuas. Observou-se que o potencial transformador das diferentes tecnologias, materializadas em dispositivos e plataformas variadas enfrentam resistência por parte dos sujeitos/autores, alunos e professores. Ambos necessitam estar capacitados frente às novas mudanças educacionais com a flexibilidade de aprender e ensinar, compartilhando materiais de aprendizado. Esta pesquisa pretende fazer o leitor reconhecer a tecnologia como aliada da educação geradora de integração social, cabendo solucionar os limites existentes para que assim usufrua das várias possibilidades que há na usabilidade do AVA.
\end{abstract}

PALAVRAS-CHAVE: Ambientes Virtuais de Aprendizagem. Formação docente. Coaprendizagem. Ensino Médio.

\begin{abstract}
Virtual Learning Environment (VLE) is the entire space that delivers content through technological media with synchronous and asynchronous communications between participants in the distance modalities, also called cyberspace. This article aims to recognize the VLE and its set of media as a dialogical object in the classroom, discussing training to the teacher, which is one of the major challenges for the handling of technological resources, especially with regard to the proposal of the virtual environment through Distance Education (DE) as mediation in the teaching and learning process in high school. The study refers to a descriptive bibliographic research with a qualitative approach. Educational changes require a new attitude from the educator and it is his / her competence to have digital fluency and to effectively master the new digital educational tools, acquiring an innovative pedagogical practice, stimulating learning and collaborating in the construction of critical and reflective citizens through continuous pedagogical-technological training. It was observed that the transforming potential of different technologies, materialized in different devices and platforms, faces resistance from the subjects / authors, students and teachers. Both need to be trained in the face of new educational changes with the flexibility to learn and teach by sharing learning materials. This research aims to make the reader recognize technology as an ally of education that generates social integration, and it is up to the existing limits to be solved so that they can take advantage of the various possibilities that exist in the usability of AVA.
\end{abstract}

KEYWORDS: Virtual Learning Environments. Teacher training. Co-learning. High school.

1 Graduação Tecnologia em Análise e Desenvolvimento de Sistemas UNOPAR (2016). Pós-graduação Tecnologias e Educação Aberta e Digital - UFRB (2020). Administradora da Karlus.net (Informática e Designer Gráfico). Professora de Informática. Habilitada em Normas ABNT aplicadas em trabalhos científicos. 


\title{
RECIMA21 - REVISTA CIENTÍFICA MULTIDISCIPLINAR
}

\author{
AMBIENTES VIRTUAIS DE APRENDIZAGEM: LIMITES E POSSIBILIDADES \\ PARA UTILIZACÃO NO ENSINO MÉDIO \\ Claudinete de Jesus da Silva
}

\section{INTRODUÇÃO}

A utilização das Tecnologias Digitais de Informação e Comunicação (TDIC) está cada dia mais crescente, difundida e as instituições educacionais contemporâneas têm buscado o AVA como ferramenta de apoio na web que vem se tornando como um suporte intrínseco no processo de ensino e aprendizagem. Desenvolveu-se originalmente na concepção epistemológica interacionistaconstrutivista numa abordagem sistêmica e de auto-organização. A adaptação e o reconhecimento deste atrativo como ciberespaço superam limites e espaços temporais existentes tornando a sala de aula física mais dinâmica e socializadora com discentes mais participativos e autônomos.

Segundo SANTOS (2003), Ambientes Virtuais de Aprendizagem (AVAs) podem ser definidos como ambientes na web utilizados por educadores, comunicadores e técnicos em informática para o desenvolvimento de interação síncrona e assíncrona entre professores e alunos que se encontram geograficamente separados. Além disso, um AVA tem a característica de agregar diferentes ferramentas e funcionalidades que permitem o acesso a conteúdos e a realização de atividades propostas de uma determinada disciplina, dentre outros recursos. Para ser possível este aprendizado por este meio, é necessário o uso de tecnologias como o computador e a internet.

O objetivo de introduzir novas tecnologias na escola é para fazer coisas diferentes e pedagogicamente importantes que não se pode realizar de outras maneiras. Utilizando novos métodos e novas estratégias a escola passa a ser um lugar mais interessante que prepararia o aluno para o seu futuro que no EaD centra-se nas capacitações individuais e coletivas.

Este artigo apresenta uma reflexão acerca da inserção das tecnologias educacionais de forma significativa, criativa e inovadora, levando em consideração as limitações apresentadas pelos professores e instituições, visando a interação do processo de coaprendizagem ${ }^{1}$.

O estudo busca responder à seguinte pergunta problematizadora: quais os empecilhos dos professores para introduzir recursos tecnológicos de informação no ensino formal?

Tendo como objetivo geral reconhecer o AVA e o seu conjunto de mídias como objeto de interação dialógica entre docentes e discentes do ensino médio no processo de ensino e aprendizagem colaborativo.

Como objetivos específicos o estudo visa: a) refletir sobre o uso de recursos tecnológicos digitais pelos docentes do ensino médio; b) apresentar as vantagens da interação digital no ensino médio por meio de ferramentas e plataformas digitais possibilitando a autoaprendizagem dos estudantes associando o plano pedagógico ao ambiente virtual a fim de preparar o cidadão crítico do futuro.

\footnotetext{
${ }^{1}$ Aprendizagem aberta colaborativa para a construção de conhecimento acessível a todos através das novas tecnologias.
}

ISSN: 2675-6218 - RECIMA21 - Ciências Exatas e da Terra, Sociais, da Saúde, Humanas e Engenharia/Tecnologia 


\title{
RECIMA21 - REVISTA CIENTÍFICA MULTIDISCIPLINAR
}

\author{
AMBIENTES VIRTUAIS DE APRENDIZAGEM: LIMITES E POSSIBILIDADES \\ PARA UTILIZAČ̃̃ NO ENSINO MÉDIO \\ Claudinete de Jesus da Silva
}

Essa investigação se deu através de pesquisa do tipo bibliográfica com a tipologia descritiva. Quanto à abordagem será qualitativa procurando entender o fenômeno específico com profundidade.

\section{ASPECTOS CONCEITUAIS DE AVA}

Basicamente pode-se definir que AVA é uma ferramenta de mídia que está sendo empregada para mediar a Educação à Distância que vem ganhando cada vez mais destaque devido ao aumento da procura por cursos online com e-learning. É uma sala de aula virtual que permite acessar conteúdo e interagir com outros alunos e com o professor, porém em instituições públicas existem vários desafios a serem enfrentados.

A EaD no Brasil surge em ambiente de muitas críticas pelos educadores, no que diz respeito à qualidade do ensino e dos serviços oferecidos por esta modalidade de ensino, especialmente a partir de seu desenvolvimento no século XIX.

Segundo VILLELA E MESQUITA (2018),

A primeira geração de AVA tem como característica o ensino por correspondência, no qual o material de estudo era encaminhado por correio tradicional e a troca de informações entre o educador e os estudantes levava tempo, no Brasil, antes mesmo de 1900 no Rio de Janeiro, era ofertado cursos profissionalizantes de datilografia por meio de anúncios de jornais. $\mathrm{O}$ rádio também contribuiu para o ensino a distância, quando da função da Rádio Sociedade no Rio de Janeiro que utilizava programas educativos para disseminar a educação popular por meio do seu sistema de Radiodifusão.

Haja vista que o Ambiente Virtual surgiu como uma necessidade social para atender as pessoas que utilizavam os serviços à distância como dos correios. E devido ao avanço tecnológico, de se simular uma sala de aula como um atrativo incentivador para estes estudantes, dá-se iniciando os ciberespaços. Percebeu-se que era preciso interagir as pessoas umas com as outras e não apenas no ambiente físico, mas também online. Os alunos não queriam apenas assistir um conteúdo e ter que anotá-lo ou carregar papeis, mas sim poder ter acesso ao que the for ensinado a qualquer momento, inclusive após a conclusão de uma aula, curso ou treinamento, pois todo o material didático fica sempre disponível no AVA.

A flexibilidade é uma das possibilidades que a modalidade da EaD proporciona, pois, o aluno tem autonomia para administrar seu local e horário de estudos de acordo com as suas necessidades pessoais e otimiza o seu método de aprendizagem.

Percebe-se que essa modalidade de ensino passou pela fase da correspondência, do rádio e da televisão, até chegar aos vários meios de comunicação que conhecemos hoje. No Brasil, a EaD desde o seu início vem ganhando cada vez mais espaço e força no cenário educacional com ofertas de cursos profissionalizantes, de aperfeiçoamento, cursos técnicos, de graduação, pós-graduação, dentre outros.

O AVA encontra-se na sua quinta geração segundo VILLELA E MESQUITA (2018), pois, foi inaugurado a partir de 2005 e perdura até os dias atuais. Neste recorte temporal o que se define é o 


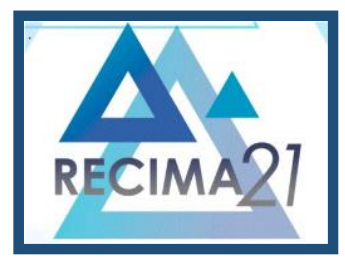

\section{RECIMA21 - REVISTA CIENTÍFICA MULTIDISCIPLINAR}

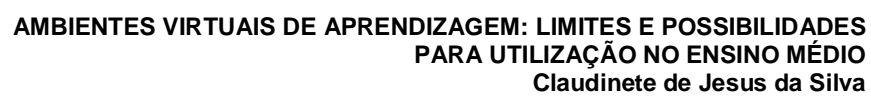

escopo legal da EaD no Brasil, primeiro com o Decreto 5.622/2005 que define a modalidade de EaD a qual a mediação didático-pedagógica se dá por meio da utilização de ferramentas tecnológicas, tais quais os Ambientes Virtuais de Aprendizagens, blogs, sites, em que os educadores e alunos se encontram situados em ambientes diversos e conectados pelas tecnologias da informação e da comunicação.

Com este progresso entra também em ação o ensino híbrido, é o que existe de mais inovador, pois obtém a unção do ensino tradicional com o ensino online através dos AVAs, neste modelo, é ampliado o espaço da sala de aula física para o ciberespaço.

HORN e STAKER (2015) definem o ensino híbrido como um aprimoramento para a educação,

Ensino Híbrido é qualquer programa educacional formal no qual um estudante aprende, pelo menos em parte, por meio do ensino on-line, com algum elemento de controle do estudante sobre o tempo, o lugar, o caminho e/ou ritmo. Atualmente existem inúmeros Ambientes Virtuais de Aprendizagem no mercado, alguns pagos e outros gratuitos, como: TelEduc, BlackBoard Learn, Moodle, dentre outros.

Vê-se que esta vasta opção de ferramentas e recursos já desenvolvidos ou que vierem a desenvolver como também o Google Classroom, LmsEstudio, para uso na educação baseadas na web, tem o objetivo de incentivar, instigar e apoiar o ensino presencial moldando ao seu melhor modo de aprender e ensinar.

De acordo com MILLIGAN (1999), a gestão de aprendizado no AVA deve-se a disposição de materiais por intermédio de ferramentas como controlar o acesso, geralmente realizado através de senha; na administração se refere ao acompanhamento dos passos do estudante dentro do ambiente, registrando seu progresso por meio das atividades e das páginas consultadas; o controle de tempo é feito através de algum meio explícito de disponibilizar materiais e atividades em determinados momentos do curso, por exemplo, o recurso calendário; a avaliação: usualmente formativa em escrita e anexar como documento, ou através de web conferência (ex. BigBlueButton), vídeo chamadas (ex. Google duo); desta forma a comunicação é promovida de forma síncrona e assíncrona; no que condiz ao espaço privativo, este precisa estar disponibilizado para os participantes trocarem e armazenarem arquivos como também haver o gerenciamento de uma base de recursos como forma de administrar recursos menos formais que os materiais didáticos, tais como (perguntas frequentes) e sistema de busca.

No entanto, a escolha do AVA para a implementação deverá ser realizada pela equipe institucional e de acordo com as funções e necessidades adequadas para o alunado destinado. Ao escolher as ferramentas, é necessário ter conexão de internet com qualidade e utilizar de forma correta trarão aos participantes, suporte, colaboração e interação no processo de ensinoaprendizagem.

Segundo BRASIL (1998), o EaD pode ser ofertada na educação básica (ensino fundamental e médio) e no ensino superior, introduzida de acordo com a Legislação Educacional 


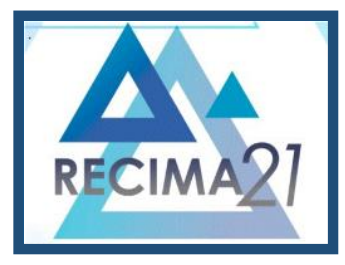

\section{RECIMA21 - REVISTA CIENTÍFICA MULTIDISCIPLINAR}

AMBIENTES VIRTUAIS DE APRENDIZAGEM: LIMITES E POSSIBILIDADES

PARA UTILIZAÇ̃̃O NO ENSINO MÉDIO Claudinete de Jesus da Silva

Brasileira de 1996 e regulamentada somente em 1998 pelos Decretos ํㅡ 2.494 de 10 de fevereiro de 1998 e 2.561 de 27 de abril de 1998.

Também reconhecem que a EaD tem características e linguagens próprias que demandam "administração, desenho, lógica, acompanhamento, avaliação, recursos técnicos, tecnológicos, de infraestrutura e pedagógicos condizentes". (BRASIL, 2007).

Para tanto, o avanço deste tipo de modalidade vem tomando espaço e requer um Projeto Político Pedagógico - PPP bem definido que esclareça as maneiras da concepção de educação e currículo no processo de ensino aprendizagem. É uma oportunidade de desenvolver novas habilidades e competências tanto do professor quanto do aluno em todos os níveis escolares mostrados pelo Decreto acima.

\section{NA PRÁTICA DOCENTE E OS SEUS DESAFIOS}

A inserção das tecnologias na educação enriquece os recursos que auxiliam na prática pedagógica docente. Construir metodologias inteligentes e significativas observando ambos os lados e as limitações que surgem no decorrer das mesmas é de organização da coordenação pedagógica e com os docentes de cada disciplina.

A tecnologia por si só não representa uma nova prática pedagógica e nem o seu uso como ilustração tecnológica na sala de aula. Funciona como uma mediação colaborativa, como uma âncora para aplicar os conteúdos contemplados no currículo escolar.

As mídias digitais possuem um grande poder pedagógico, e o professor precisa conhecer as possibilidades metodológicas que estas possuem para aplicar conteúdos dinamizados e interativos com o objetivo de tornar mais ampliado e reflexivo o modo de aprender do aluno, mudando o seu jeito de pensar.

No entanto, observa-se que o potencial transformador das diferentes tecnologias, materializados em dispositivos móveis, plataformas, aplicativos e outros enfrentam, muitas vezes, resistência por parte dos sujeitos, tanto dos alunos quanto professores. BASTOS (2016).

Mesmo havendo resistência no uso de recursos tecnológicos, sabe-se que a tecnologia tem em sua essência o poder de transformar seres humanos em mais racionais e autodidatas, tornandoos autores das suas próprias histórias. O professor também produz a sua autoria, ele não dita, ele aponta caminhos ao dar todo o suporte necessário tanto tecnológico quanto pedagógico para 0 aluno, contudo, ambos necessitam estar capacitados frente às novas mudanças educacionais.

VALENTE (1993) esclarece que,

A função do aparato educacional deve ser de promover o aprendizado onde o professor deixa de ser mero repassador do conhecimento, para ser o criador de ambientes de aprendizado e facilitador do processo pelo qual o estudante adquire novos conhecimentos. 


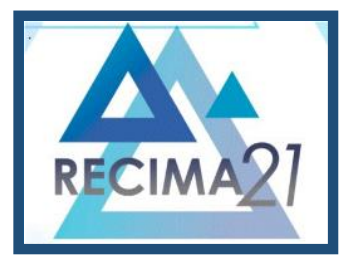

\section{RECIMA21 - REVISTA CIENTÍFICA MULTIDISCIPLINAR}

\section{AMBIENTES VIRTUAIS DE APRENDIZAGEM: LIMITES E POSSIBILIDADES \\ PARA UTILIZAÇÃO NO ENSINO MÉDIO Claudinete de Jesus da Silva}

Neste espaço, o professor atuante em sua função no processo de ensino e aprendizagem criará um ambiente flexível que facilite e crie novas expectativas no olhar do educando para que este adquira o seu conhecimento com significância com uma experiência modelada de aprendizagem.

É de competência do professor dominar o conteúdo curricular agregado ao conhecimento crítico das tecnologias educacionais que rapidamente se tornam arcaicas, afim de instaurar as diferenças de qualidades nas atividades pedagógicas, estimulando a criatividade, a autonomia e a formação do aluno coautor.

Portanto, para que haja uma sincronia de saberes e o projeto do professor no ensino e na aprendizagem em ambientes e cenários digitais emergentes seja totalmente colocado em prática, faz-se necessário haver formação pedagógica integrada à tecnológica contínua para compreender a sua aplicação através de experiências e práticas e assim desenvolver suas capacidades técnicas e simultaneamente as suas capacidades pedagógicas, estando apto a pensar e aprender a aprender.

O Conselho Nacional de Educação (CNE) em seu Art. $8^{\circ}$ relata que no egresso dos cursos de formação, o professor deve estar apto de acordo com o capítulo $\mathrm{V}$ a: relacionar a linguagem dos meios de comunicação à educação, nos processos didáticos pedagógicos, demonstrando domínio das tecnologias de informação e comunicação para o desenvolvimento da aprendizagem.

Diante da visão do Conselho, vê-se que relacionar é interagir, e interação é um dos maiores valores deste tempo de tecnologias e mudanças repentinas presentes na $\mathrm{EaD}$, ela está entre as pessoas, os seus pensamentos e suas ações. A interatividade precisa ser recorrente e as dúvidas no decorrer das aulas precisam ser sanadas em tempo hábil dentro do processo do desenvolvimento intelectual.

O docente ao se adequar ao AVA verá novas formas de ensinar, podendo obter e intermediar informações em fontes de lugares distintos de instituições como centros de pesquisas, universidades, bibliotecas, permitindo assim trabalhos em parcerias com escolas de outras cidades, tendo a possibilidade de realizar conexões com alunos da mesma rede municipal a qualquer hora, beneficiando no desenvolvimento dos trabalhos com a troca de informações entre escolas de outros estados, ou mesmo a experiência de webconferência com um palestrante, como também participação em seminários e apresentações (orais, slides), ampliando o conhecimento cientifico e cultural dos educandos.

As novas tecnologias colaboram no aprendizado a partir do instante em que o professor se apropria desse conhecimento, mas infelizmente a formação ainda é carente. Há no professor o desejo de aprender, mas ele não sabe para onde ou como ir. (FONTOURA apud TRUJILLO, 2018).

Contudo, para que seja eficaz a aplicação de tecnologias na sala de aula, ou fora desta, o educador precisa de formação continuada constante para que consolide este novo modo de ensinar e assegurar que o ensino seja de qualidade. Para confirmar a informação dos autores, a Revista Educação (2018) realizou uma pesquisa sobre a formação dos professores numa instituição qual 


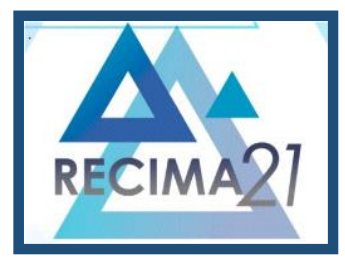

\section{RECIMA21 - REVISTA CIENTÍFICA MULTIDISCIPLINAR}

\section{AMBIENTES VIRTUAIS DE APRENDIZAGEM: LIMITES E POSSIBILIDADES \\ PARA UTILIZAČ̃̃ NO ENSINO MÉDIO Claudinete de Jesus da Silva}

obteve o resultado de que $54 \%$ dos educadores não cursaram na graduação uma disciplina específica acerca de como fazer uso de computador e da internet em exercícios para os estudantes. $70 \%$ não tiveram formação continuada sobre o tema no ano antecedente ao levantamento. Dentre os participantes apenas $20 \%$ falaram que a capacitação contribuiu bastante para a atualização na área.

Pode-se perceber que os números da pesquisa comprovam que a formação do professor é um fator considerado como um dos principais desafios quando se refere a correta usabilidade das tecnologias no âmbito escolar.

O Ambiente Virtual possibilita ainda ao docente participar e desenvolver um conjunto de atividades de interesse didático-pedagógico em formato de rede através da prática de intercâmbios científicos, como produção de textos em línguas estrangeiras, elaborações e publicações de pesquisas em conjunto que contribuirá para a sua formação avançada.

Diante de tecnologias inovadoras educacionais a serem aderidas, o papel do professor se torna diferente e sua atenção é requerida principalmente nas estratégias de ações didáticas a serem aplicadas.

$\mathrm{O}$ art. 16 da Resolução № 02/2015 - CNE/CP definiu a formação continuada como um repensar do processo pedagógico, uma busca pela reflexão e um aperfeiçoamento pedagógico.

Neste contexto de mudanças e adequações, o professor deve ainda saber orientar os estudantes sobre como colher informação, sendo de boa qualidade, realizar tratamento e como utilizá-las de forma coerente. Será o protagonista que irá encaminhar o aluno na sua autopromoção, em diversos momentos estimulando o trabalho individual, ora dando apoio aos trabalhos coletivos.

No entanto, há a necessidade de formação tecnológica integrada à pedagógica para que o professor compreenda a sua aplicação docente através de experiências e boas práticas para ampliar suas capacidades técnicas e simultaneamente as suas capacidades pedagógicas.

Segundo o (CNE) 02/2015 em seu Parágrafo Único relata que,

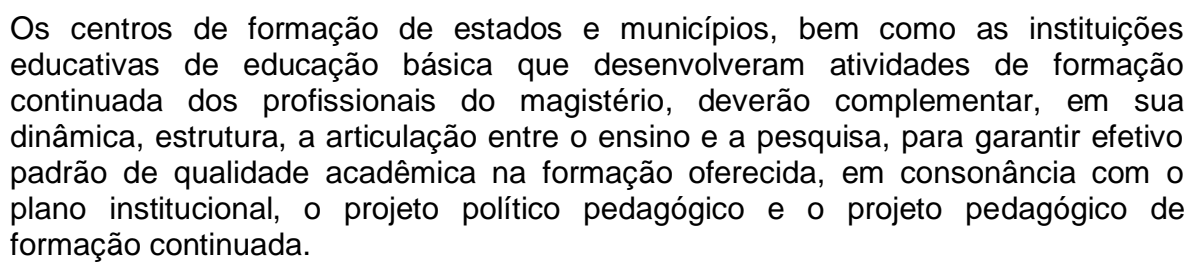

Haja vista que tanto os professores quanto a escola não podem se estagnar, devem ir além das formações, se interagir com as transformações ocorridas na sociedade e no ambiente que os cercam. Formação continuada é de nível obrigatório para aqueles que desejam oferecer um ambiente de aprendizado satisfatório e atualizado aos educandos. Ao ser proativo na sua interação, ajuda a sociedade a transformar-se e, ao mesmo tempo, em que se modifica a mesma, identificando as necessidades curriculares, pedagógicas e sociais. 


\section{RECIMA21 - REVISTA CIENTÍFICA MULTIDISCIPLINAR}

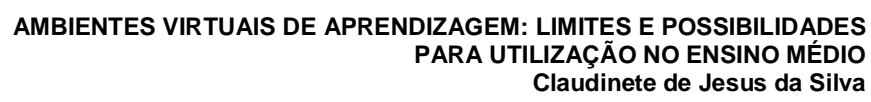

FONTOURA apud RIBEIRO (Revista Educação, 2018) relatam sobre um grande desafio nos tempos atuais em que o professor consiga compreender que a tecnologia pode volver a ação de ensino-aprendizagem para melhor. Se a formação for insuficiente, dificultará o cultivo das potencialidades pedagógicas com as novas tecnologias. Em muitos casos, pode levar a uma determinada resistência no seu uso, tornando os métodos mais tradicionais serem reproduzidos. E muitas vezes a dificuldade de criar algo a mais além das atividades do professor como planos se torna uma desconfiança por alguns docentes com relação ao uso das novas tecnologias que traz mudanças e muda a sua própria rotina das aulas.

Utilizar ferramentas tecnológicas requer um tempo a mais de estudo em casa, de um planejamento maior e mais diferenciado, de um período semanal que exige reflexão. Outro fator que causa desconfiança no docente é o medo de a tecnologia atuar como um distrator. No uso da internet, por exemplo, o receio é que os alunos desviem a atenção do conteúdo da aula para as suas redes sociais pessoais.

Diante do exposto, afirma-se que o docente se encontra confuso e com muitas desconfianças diante de tantas provocações que podem ocorrer com o acesso das tecnologias na educação e dessa forma gera uma resistência maior à sua inserção.

Compreender e disponibilizar de tempo para dominar as ferramentas tecnológicas, percebendo que estas colaboram ao invés de atrapalhar é de suma importância para haver no exercício docente uma exploração pedagógica ampla e concreta e que esteja interessado em fazer parte de cursos formativos. Estando preparados para conservar a atenção do educando no aprender e colaborar no seu desenvolvimento e consequentemente gerando a coaprendizagem.

Diante deste fato, OKADA (2012) corrobora que,

Através da coaprendizagem enfatiza a importância do papel dos professores, como distribuidores de conhecimento e dos estudantes que recebem conteúdos, para a colaboração no processo de aprendizagem. Seu conteúdo é resultado de várias adaptações feitas por diferentes pessoas usando diferentes tecnologias.

Vale ressaltar que o professor precisa compreender o seu papel de distribuir conhecimento e conseguir proporcionar ao aluno um ambiente rico em conteúdo tendo a confiança de que este material inovador de tecnologias irá norteá-lo.

MOREIRA, BARROS e MONTEIRO (2015), acerca de cenários virtuais de aprendizagem, mostram a coaprendizagem como uma estratégia didática pedagógica emergente para a educação em todos os âmbitos, tanto formal quanto informal, realizados nos diversos cenários e espaços.

Porém, para que essa mudança ocorra, é necessário, por um lado, que se valorize institucionalmente a Educação Digital, ou seja, que se valorizem as práticas pedagógicas enriquecidas com tecnologias digitais e, por outro lado, que seja realizado um investimento na formação dos professores para saber utilizá-las.

Nesse contexto, o modelo teórico Technological Pedagogical Content Knowledge (TPACK) pode assumir um papel central, uma vez que reconhece a necessidade de integrar a tecnologia sem 


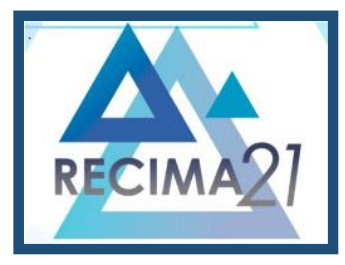

\title{
RECIMA21 - REVISTA CIENTÍFICA MULTIDISCIPLINAR
}

\author{
AMBIENTES VIRTUAIS DE APRENDIZAGEM: LIMITES E POSSIBILIDADES \\ PARA UTILIZACC̃̃O NO ENSINO MÉDIO \\ Claudinete de Jesus da Silva
}

negligenciar a natureza complexa, multifacetada e situada de conhecimento dos professores. (DIAS e MOREIRA, 2018).

Para tanto, o professor tem um total amparo ao obter formação continuada específica a fim de conceber um ensino de maior condição aplicando os recursos tecnológicos, fazendo a interligação com os conhecimentos pedagógicos e/ou científicos.

Segundo dados da Revista Espácios (2018, p. 5), ao comparar as quantidades de ferramentas metodológicas atuais em relação às existentes há algumas décadas, percebe-se que houve um grande avanço e que as inovações tecnológicas são equipamentos facilitadores da aprendizagem.

Todavia, para que os avanços tecnológicos atuem como eficientes instrumentos no processo de ensino-aprendizagem há que se superar um gargalo: o baixo nível de conhecimento prático e técnico das práticas tecnológicas em sala de aula, além da falta de domínios sobre os recursos tecnológicos por parte de alguns educadores bem como também há carência na estrutura humana e tecnológica.

\section{MEDIANDO O ENSINO MÉDIO COM AVA}

Os Ambientes Virtuais de Aprendizagem para BARBOZA, SALES FILHO e SILVA (2016), são definidos como softwares usados para o gerenciamento do processo de ensino e aprendizagem utilizando do computador e de métodos de ensino para cursos/aulas online.

No que tange as possibilidades de aplicação de Ensino à Distância pelas instituições de ensino médio, a Lei de Diretrizes e Bases no 9.394 de 20 de dezembro de 1996 afirma em seu Artigo 80 que,

O Poder Público incentivará o desenvolvimento e a veiculação de programas de ensino a distância, em todos os níveis e modalidades de ensino, e de educação continuada.

$\S 1^{\circ} \mathrm{A}$ educação à distância, organizada com abertura e regime especiais, será oferecida por instituições especificamente credenciadas pela União.

Ainda na Lei de Diretrizes e Bases no 9.394 de 20 de dezembro de 1996 Art. 35, o ensino médio, etapa final da educação básica, com duração mínima de três anos, terá dentre suas finalidades, as seguintes:

II - a preparação básica para o trabalho e a cidadania do educando, para continuar aprendendo, de modo a ser capaz de se adaptar com flexibilidade a novas condições de ocupação ou aperfeiçoamento posteriores;

III - o aprimoramento do educando como pessoa humana, incluindo a formação ética e o desenvolvimento da autonomia intelectual e do pensamento crítico; IV - a compreensão dos fundamentos científico-tecnológicos dos processos produtivos, relacionando a teoria com a prática, no ensino de cada disciplina.

Nesse sentido, cabe às instituições escolares zelar e colocar em prática estas LDBs citadas para que os discentes nessa interação teórica e prática concluam o ensino médio, capacitados e 


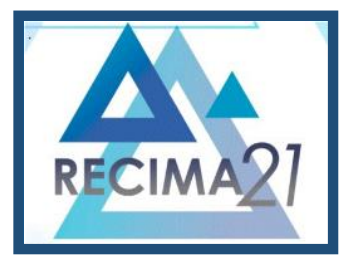

\title{
RECIMA21 - REVISTA CIENTÍFICA MULTIDISCIPLINAR
}

\author{
AMBIENTES VIRTUAIS DE APRENDIZAGEM: LIMITES E POSSIBILIDADES \\ PARA UTILIZAÇ̃̃O NO ENSINO MÉDIO \\ Claudinete de Jesus da Silva
}

preparados intelectualmente possibilitando o desenvolvimento da sua criticidade nos campos pessoal e profissional.

Segundo MERCADO (2002),

\begin{abstract}
As instituições escolares enfrentam o desafio não apenas de incorporar para as novas tecnologias como conteúdos de ensino, mas também reconhecer a partir das concepções que os estudantes têm sobre estas tecnologias para elaborar, desenvolver e avaliar práticas pedagógicas que promovam o desenvolvimento de uma disposição reflexiva sobre os conhecimentos e os usos tecnológicos atuais.
\end{abstract}

Para o autor, o aluno necessita assim como o professor reconhecer que as tecnologias educacionais são instrumentos enriquecedores de aprendizagem que melhora as condições do aprender acrescido de mais praticidade na rede compartilhada, obtendo mais flexibilidade no uso de aplicativos nos dispositivos móveis e de mesa para se interagirem bem e cooperarem mutuamente.

A educação aberta colaborativa tem se mostrado como peça fundamental na educação que amplia a aprendizagem ao longo dos tempos e está proporcionando a oportunidade de construir novos conhecimentos com o uso das redes e das mídias sociais. Este conjunto de Recursos Educacionais Abertos, mais conhecido como $R E A^{2}$, oferece o uso livre dos conteúdos dispostos ampliando o crescimento coletivo.

Quando no âmbito externo da escola todos os alunos que farão parte do benefício da EaD precisam ter acesso à internet, seja por computadores públicos ou privados, notebooks, smartphones, para que possam acompanhar, interagir, dinamizar, dentro da sala de aula virtual. Dentre mais possibilidades, os discentes podem construir produções a serem compartilhadas em diversos formatos tais como textos, apresentações, vídeos, áudios e até mesmo outros aplicativos que acessem as diversas mídias atuais. Expostos dentro do AVA de forma criativa e dinâmica para que o aluno seja engajado e tenha anseio de aprender e querer ser um sujeito autônomo.

Contudo, SILVA e CAMPOS (2016) mostram para um "descompasso entre a tecnologia utilizada na escola e o recurso na mão do aluno". O descompasso dar-se início com a dificuldade que muitos professores têm para dominar a tecnologia e na carência da infraestrutura das escolas (falta de conexão, precariedade das redes, equipamentos obsoletos).

A limitação de conhecimento em saber usar adequadamente os recursos digitais com o objetivo de aprender é descompassado demais, esta cultura precisa ser revista. Bem como a resistência do professor ao domínio tecnológico, limitação na estrutura institucional e formação contínua para os docentes são os impedimentos encontrados para a inserção de um ambiente virtual de aprendizagem para alunos do ensino médio.

Nesse sentido, seria necessário ainda conscientizar tecnologicamente também os estudantes para compreenderem a velocidade com que as mudanças educacionais estão ocorrendo a cada dia, pois infelizmente muitos ainda não dominam a tecnologia, sendo analfabetos digitais.

\footnotetext{
2 É movimento de uma comunidade internacional impulsionado pela Internet que tem como objetivo promover o acesso, uso e reuso de bens educacionais.
} 


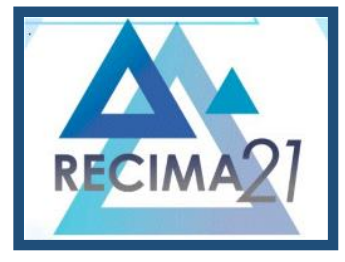

\section{RECIMA21 - REVISTA CIENTÍFICA MULTIDISCIPLINAR}

\section{AMBIENTES VIRTUAIS DE APRENDIZAGEM: LIMITES E POSSIBILIDADES \\ PARA UTILIZACCÃO NO ENSINO MÉDIO Claudinete de Jesus da Silva}

A alfabetização digital na contemporaneidade é um requisito valioso para o exercício da cidadania plena e se promove a uma democratização incluindo todos na sociedade do conhecimento. ROCHA (2018, p. 17) relembra que,

Hoje o computador faz parte do cotidiano das pessoas, as informações estão disponíveis qualquer momento através das tecnologias midiáticas, essas se tornam cada vez mais inovadoras, o que demanda novas formas de pensar, agir, conviver, e principalmente aprender, com e por meio destas.

O que garante o sucesso do uso das tecnologias na sala de aula é a capacidade de os envolvidos quebrarem os paradigmas tradicionais, "só se aprende no ensino presencial". E fica centrado na imagem em que o professor transmite o conhecimento e o aluno aprende. Com as

informações tecnológicas na modalidade $\mathrm{EaD}$ ou híbrida o aluno é responsável pela conquista do seu conhecimento.

Vale salientar que a incorporação das novas tecnologias como conteúdos básicos comuns é um elemento que pode contribuir para uma maior vinculação entre os contextos de ensino e as culturas que se desenvolvem fora do âmbito escolar. MERCADO (2002).

O objetivo essencial do ensino com metodologias tecnológicas é trazer para dentro da sala de aula, as tecnologias que os alunos e professores já utilizam fora desta, porém, como instrumento de aprendizado. Nesse contexto do ensino médio pode ainda utilizar/conectar o ensino híbrido, que é a metodologia que combina aprendizado online com o offline, em modelos que mesclam (por isso o termo blended, do inglês "misturar") momentos em que o aluno estuda sozinho, de maneira virtual, com outros em que a aprendizagem ocorre de forma presencial, valorizando a interação entre pares e entres alunos.

Dentro dos ambientes virtuais ocorre o processo que media. Segundo FRANCK e NICHELE (2015),

Deve estar relacionado a autonomia, a qual permite que estudantes possam ter
aptidão de resolver problemas de suas realidades com mais segurança, um
processo que fomenta no próprio estudante a descoberta de suas potencialidades
em que aquele que está sendo mediado aprende a aprender. Parte-se então desta
condição que o AVA exerce a função de mediar, seja pela conexão entre o aprendiz
e o que se ensina e dele como ele mesmo, pois é desafiado a aprender
aprendendo.

Ressalta-se que o ensino e a aprendizagem atualmente são uma demanda social e não mais uma questão de luxo é ir ao encontro da grande maioria dos alunos que estão atualizados tecnologicamente nas redes e mídias sociais fora da escola. Basta que se aproximem e vejam com novos olhos a tecnologia como mediadora do aprender. 


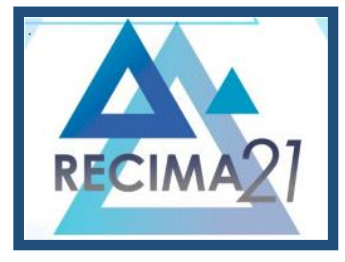

\section{RECIMA21 - REVISTA CIENTÍFICA MULTIDISCIPLINAR}

\section{AMBIENTES VIRTUAIS DE APRENDIZAGEM: LIMITES E POSSIBILIDADES \\ PARA UTILIZAČ̃O NO ENSINO MÉDIO Claudinete de Jesus da Silva}

Pode-se citar como exemplo de AVA, o Moodle que é uma grande e poderosa plataforma, pois contempla uma quantidade significativa de recursos como mostra na imagem abaixo podendo ser utilizado no ensino híbrido:

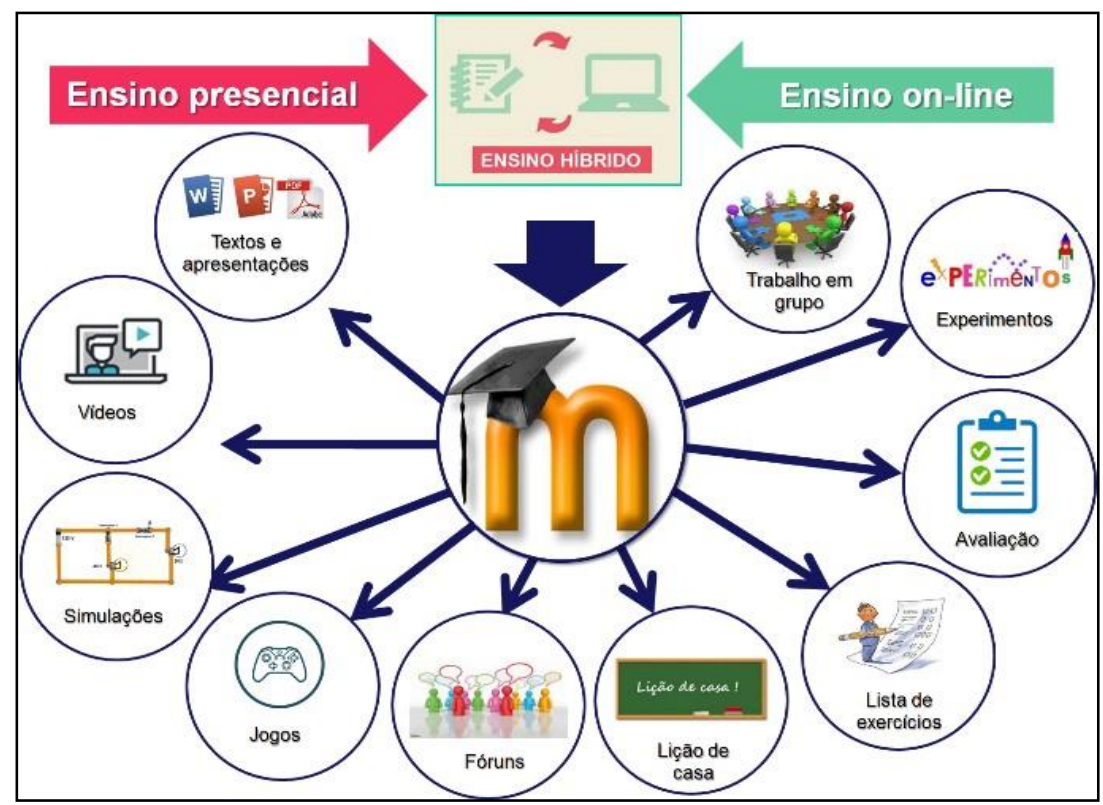

Figura 01 - Recursos e Atividades disponibilizados no Moodle.

Ao observar a figura acima que representa o Moodle, percebe-se a conexão de proximidade de todo o material necessário para o curso. Oferta a flexibilidade de aprender em conjunto e compartilhar materiais sendo de grande importância e praticidade este acesso no Ambiente Virtual, ficando disponibilizados especificamente os conteúdos das disciplinas pelos docentes, para que os alunos explorem os livros didáticos, obras literárias, textos de produções e interpretações, vídeos e demais recursos didáticos reduzindo a realização de impressões, o que viabilizaria economia para a instituição e para o meio ambiente.

Dessa forma os alunos vivem experiências parecidas de colaboração mútua e desenvolvem a consciência com relação as suas próprias ações dentro do ciberespaço, caminhando de modo autônomo e tendo responsabilidade na sua construção, pois o colega se constrói de acordo com o seu crescimento, associando ao processo de andaimagem no ponto de vista interacionista de Vygotsky, onde um sujeito mais capaz dê suporte a outro a fim de solucionar um problema ao qual ainda não estaria apto a resolver, como também caracteriza o aprendizado como um fenômeno que acontece na interação social.

O AVA é uma sala de múltiplas facetas e funções com o fim de atender bem os desafios propostos para cada turma. É transportar a pedagogia que se usa na sala de aula física para uma sala de aula virtual. O ensino aprendizado acontece da mesma forma, o que muda é o caminho e o 


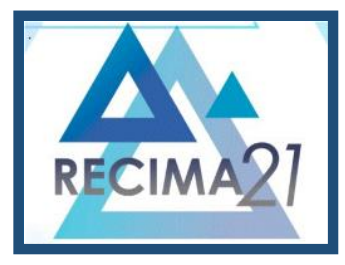

\title{
RECIMA21 - REVISTA CIENTÍFICA MULTIDISCIPLINAR
}

\section{AMBIENTES VIRTUAIS DE APRENDIZAGEM: LIMITES E POSSIBILIDADES \\ PARA UTILIZACCÃO NO ENSINO MÉDIO Claudinete de Jesus da Silva}

lugar para a interação e a absorção do conhecimento, $\mathrm{O}$ que se espera de cada estudante é que possua o poder de ter um relacionamento mais próximo com os colegas e professores através de bate papo, realimentação, envio e contemplação de atividades, avaliações escolares, é deixar se envolver para acontecer o seu aprendizado.

Acerca dessa afirmativa FOFONCA, SCHONINGER e COSTA (2018), discorrem que,

\begin{abstract}
Por meio da interação dos professores e alunos os quais são expostos a troca de experiências entre si, seja pela proposta de curso ou de realização de atividades, fazendo-os participar ativamente do que se é solicitado para o ensino e aprendizado de conteúdos relevantes, neste interim o feedback de ambos permite que estes sejam coautores do conhecimento que é elaborado no AVA ou através dele.
\end{abstract}

De acordo com os autores, essa interatividade se torna uma condição interdependente entre os coautores: docentes $x$ discentes $x$ colegas é o que favorece a aprendizagem de acordo com 0 nível de cada um. Todos aprendem com a troca de informações e a produção de saberes, um depende da colaboração do outro.

Para tanto pode-se acrescentar no AVA um recurso muito interessante na rede que é o REA, está baseado na ideia de bens comuns. Uma definição formal construída em colaboração com a comunidade REA no Brasil foi adotada pela UNESCO/COL: Os REA são materiais de ensino, aprendizado e pesquisa em qualquer suporte ou mídia que estão sob domínio público, ou são licenciados de maneira aberta, permitindo que sejam acessados, utilizados, adaptados e redistribuídos por terceiros. $O$ uso de formatos técnicos abertos facilita o acesso e reuso potencial dos recursos.

Os REA podem incluir cursos completos, partes de cursos, módulos, guias para estudantes, anotações, livros didáticos, artigos de pesquisa, vídeos, instrumentos de avaliação, recursos interativos como simulações e jogos de interpretação, bancos de dados, software, aplicativos (incluindo versões para dispositivos móveis) e qualquer outro recurso educacional de utilidade. $O$ movimento REA não é sinônimo de aprendizado online, EaD ou educação por meio de dispositivos móveis. Muitos REA, mesmo que possam ser compartilhados por meio de formatos digitais, também podem ser impressos.

OKADA (2012) define REA da seguinte forma,

O que? (título), quem? (autores + autores anteriores), onde? (fonte), como? (descrição), por quê? (objetivo + licença). A mídia social e REA são, portanto, muito relevantes para proporcionar oportunidades amplas de partilha e aprendizado coletivo, no qual os usuários podem aprender com as produções e formas de produzir dos outros. Quando o produto educacional e o processo são abertos, os aprendizes podem reutilizar não só o seu conteúdo, mas também, as tecnologias e métodos.

De acordo com o parecer da autora, compreende que as redes e mídias sociais estão ainda mais recheadas com oportunidades de aprendizado para todos produzirem e reproduzirem o seu 


\section{RECIMA21 - REVISTA CIENTÍFICA MULTIDISCIPLINAR}

AMBIENTES VIRTUAIS DE APRENDIZAGEM: LIMITES E POSSIBILIDADES PARA UTILIZAÇÃO NO ENSINO MÉDIO Claudinete de Jesus da Silva

próprio conhecimento. Cotidianamente são modificadas as maneiras individuais e coletivas de comunicar e aprender uns com os outros agregados ao Ambiente Virtual da escola.

Contudo, fazer uso do celular na sala de aula como recurso pedagógico de forma consciente é uma opção válida e acertada para acessar ambientes virtuais diretamente da sala de aula com a ministração do professor.

Essas práticas inovadoras valorizam a efetividade dos coautores como o diálogo, a participação constante de todos, pois no ciberespaço ocorre o processo de andaimagem ${ }^{3}$ para a contribuição e apoio no crescimento intelectual de cada educando.

Vale ressaltar ainda que a ampla vantagem de uso de recursos da EaD como um método interacional no ensino médio destaca-se em adaptar as realidades diferentes dos que procuram formação, como resgatar jovens para acesso à educação, que por algum motivo não pôde dar continuidade aos estudos no ensino presencial, indo ao encontro de umas das principais características da EaD que é de extrapolar os muros da escola, é um modelo novo, incentivador a estes jovens dando a oportunidade de ser mais flexível as suas necessidades.

É possível ainda utilizar em sala de aula com o auxílio dos smartphones, entre outras ferramentas, aplicativos que permitem gamificar as aulas, por exemplo, o Kahoot que os seus jogos de aprendizado, são testes de várias escolhas, permitindo aos usuários acessarem através de um navegador ou pelo aplicativo no smartphone. Desta forma permite, motiva, descontrai e atrai o olhar dos educandos através de jogos e competições, que colabora grandemente na aprendizagem.

A avaliação do Ambiente Virtual se dar através das participações nas ferramentas como chats, fóruns, postagem de trabalhos de acordo com a solicitação do professor e prazo de entrega garantindo a interação social entre os estudantes e os professores.

Vale acrescentar ainda que dentro do AVA pode inserir o formulário Google com as provas que corrigirá as questões-testes de forma automática colaborando com o resultado ágil que poderá ser encaminhado por e-mail para o aluno e o ganho de tempo do professor na correção, bem como na redução de impressões.

A prática avaliativa no AVA pode-se ocorrer também com aplicações de atividades individuais ou coletivas, de acordo com a organização metodológica do professor que pode criar estratégias avaliativas que valorizem uma proposta de avaliação colaborativa.

Contudo, a produção em grupo pretende na totalidade desenvolver a interação social, havendo coerência e disciplina por cada membro como deve ser numa comunidade virtual, visando os interesses coletivos, e observando no que condiz a conteúdos que algum aluno se encontra com dificuldade, sendo uma oportunidade para partilhar o aprendizado e solucionar as dúvidas existentes.

\footnotetext{
${ }^{3}$ Relacionado à interação professor/aluno em sala de aula, constituindo um conceito metafórico do auxílio visível ou audível (os andaimes) dado pelo professor como alguém mais experiente em relação ao aprendiz - aluno no processo de ensino/aprendizagem. (MAGALHÃES, Rosineide; MACHADO, Veruska Ribeiro. Leitura interação no enquadres de protocolos verbais. In: BORTONI-RICARDO, Stella Maris (orgs). Leitura e mediação pedagógica. São Paulo: Parábola, 2012.)
} 


\title{
RECIMA21 - REVISTA CIENTÍFICA MULTIDISCIPLINAR
}

\author{
AMBIENTES VIRTUAIS DE APRENDIZAGEM: LIMITES E POSSIBILIDADES \\ PARA UTILIZACÃO NO ENSINO MÉDIO \\ Claudinete de Jesus da Silva
}

\section{METODOLOGIA}

Essa investigação se deu através de pesquisa do tipo bibliografia. De acordo com VERGARA (2007), pesquisa bibliográfica é o estudo sistematizado desenvolvido com base em material publicado em livros, revistas, jornais, redes eletrônicas, isto é, material acessível ao público em geral. Este tipo de pesquisa ajuda no processo de busca do pesquisador na construção de novos trabalhos que almejam compreender diversas áreas do conhecimento e nesta ocasião procurou-se compreender a problemática que são os empecilhos encontrados pelos professores em utilizar recursos tecnológicos de informação no ensino médio.

Para LAKATOS E MARCONI (2001) os estudos descritivos destinam-se a descrever as características de determinada situação, os estudos descritivos diferem dos resultados exploratórios no rigor em que são elaborados seus projetos. Neste sentido VERGARA (2003) descreve a pesquisa descritiva como aquela que expõe características de determinada população ou de determinado fenômeno, podendo ainda estabelecer correlações entre variáveis e definir sua natureza.

Quanto à abordagem será qualitativa é basicamente aquela que procura entender um fenômeno específico em profundidade. MARTINS e THEÓFILO (2007, p. 137) destacam que os dados devem ser predominantes descritos; é necessário registrar a descrição. "[...] de pessoas, de situações, de acontecimentos, de reações, inclusive transcrições de relatos". Outra característica muito importante na pesquisa qualitativa é o acompanhamento do processo, ao contrário da pesquisa quantitativa que se preocupa com os resultados.

Portanto, a tipologia da pesquisa sendo descritiva, esta tem por objetivo descrever as propriedades de uma população, de um fato ou de uma experiência. Esse tipo de pesquisa estabelece relação entre as variáveis no objeto de estudo analisado.

O procedimento utilizado para coleta de dados da pesquisa será a observação. Segundo RUDIO (2006), o método da observação "não se trata apenas de ver, mas de examinar; não se trata somente de entender, mas de auscultar". (p. 39). Contudo, busca-se saber com mais profundidade as diversas possibilidades de crescimento de educandos e educadores ao usufruírem de plataformas digitais mediando o ensino aprendizagem.

As bases de dados a serem consultadas na revisão bibliográfica estão disponíveis em livros impressos, digitais localizados na internet, em plataformas e bibliotecas digitais como, Scielo e Sucupira. A pesquisa se encontra com dados entre os anos 1995 a 2017.

\section{RESULTADOS E DISCUSSÕES}

Pode-se notar que a falta de capacitação profissional ainda é um dos grandes obstáculos para adesão dos recursos tecnológicos em sala de aula. Com formações adequadas garantiria a 


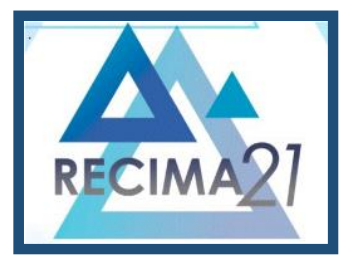

\title{
RECIMA21 - REVISTA CIENTÍFICA MULTIDISCIPLINAR
}

\author{
AMBIENTES VIRTUAIS DE APRENDIZAGEM: LIMITES E POSSIBILIDADES \\ PARA UTILIZAÇ̃̃O NO ENSINO MÉDIO \\ Claudinete de Jesus da Silva
}

valorização da identidade cultural educacional, bem como a criação e ampliação de acesso a novos conhecimentos digitais.

MERCADO (2002) destaca que,

Os professores são profissionais que tem uma função re (criadora) sistemática, sendo esta a única forma de proceder quando se tem alunos e contextos de ensino com características tão diversificadas, como sucede em todos os níveis de ensino. A função do professor é a criação e recriação sistemática, que tem em conta o contexto em que se desenvolve a sua atividade e a população-alvo desta atividade.

Portanto, o professor deve caminhar junto com o aluno, acompanhar o desenvolvimento tecnológico e social e deixar-se recriar com os ambientes virtuais de aprendizagem e com outros recursos.

É de fundamental importância que o docente se conscientize e se forme sem colocar impedimentos, dando um passo adiante, percebendo que a sociedade está cada vez mais conectada e precisa está em conjunto com a escola, acrescentando no seu currículo habilidades e competências para saber lidar com as novas tecnologias na educação, pois esse é o centro do problema para o seu uso, compreendendo que a tecnologia é um suporte aliado da educação que convida o mundo a ver os olhos com novas ópticas.

No que se refere à avaliação do estudante nas aulas síncronas, diante dos mecanismos existentes que exija sua disciplina, como o número de visitas, visualizações, comentários, participação em chats e grupos de estudos on-line, o aprendizado não pode cessar no momento em que a aula se encerra, ele continua e se estende através de outras ferramentas do AVA que podem ser acrescidas para acesso.

Percebe-se que são vários e multifacetados os meios que podem ser utilizados por docentes e discentes no campo tecnológico, possibilitando terem um desenvolvimento bem mais amplo, tanto de proximidade afetiva, cognitiva, como motivacional no ensino aprendizagem no âmbito do ensino médio através da interação dialógica que o AVA oferece.

No entanto, há ainda as limitações humanas e estruturais a serem sanadas. Cabendo a instituição observar e seguir também as políticas públicas educacionais que apontam caminhos e indicadores.

\section{CONSIDERAÇÕES FINAIS}

Acerca do estudo realizado, pode-se reconhecer que o Ensino à Distância por intermédio do AVA favorece o ensino aprendizagem de modo dinâmico e interacionista através da comunicação entre professores e alunos.

Esta modalidade apresenta-se como um veículo fascinante e enriquecedor quando em conjunto com as práticas metodológicas/pedagógicas aplicadas nos diversos campos do saber. Fica entendido que há uma meta no sistema educacional através da sua democracia digital com variadas 


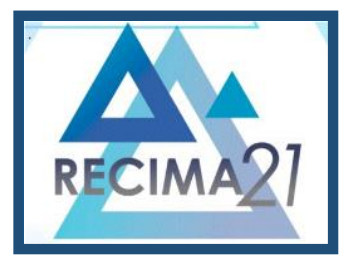

\section{RECIMA21 - REVISTA CIENTÍFICA MULTIDISCIPLINAR}

AMBIENTES VIRTUAIS DE APRENDIZAGEM: LIMITES E POSSIBILIDADES PARA UTILIZAÇÃO NO ENSINO MÉDIO Claudinete de Jesus da Silva

possibilidades que surgem a todo instante como leques de oportunidades como exemplo os REA que são materiais de ensino, aprendizado e pesquisa em qualquer suporte ou mídia que estão sob domínio público, ou são licenciados de maneira aberta, permitindo que sejam acessados, utilizados, adaptados e redistribuídos por terceiros, fazendo do reuso um grande potencial de recursos.

Nota-se que é possível praticar um ensino inovador e obter uma aprendizagem significativa dialógica, com a colaboração das plataformas digitais trazendo em seu Ambiente Virtual uma sala de aula multifacetada com os seus elementos e características próprias que dão suporte aos aprendizes, tornando alunos autodidatas com novas perspectivas, através da prática de estratégias didáticas diversificadas.

Não se nega o fato de uma falta de preparo mais abrangente do professor defronte os recursos tecnológicos em conjunto com as práticas pedagógicas utilizando as TDIC na educação, sendo este a principal dificuldade para sua aplicação. Cabe conscientizar o professor acerca das inovações do aprendizado e do crescimento ofertado no âmbito EaD e que é necessário acompanhar o avanço das tecnologias que rapidamente se tornam obsoletas e com estas mudanças exigem ainda mais dedicação, capacitação e formação contínua. O professor precisa estar de prontidão para querer aprender e desenvolver novas habilidades.

Neste processo, todos os envolvidos em especial os educandos possuirão uma postura única, transformadora e autônoma de aprender e de ensinar, contando que também necessitam estarem capacitados para compreender a dinâmica desta modalidade de ensino e obter sucesso no seu aprendizado, sem deixar de ser participativo e colaborativo com o colega.

Há também que instalar uma estrutura humana e tecnológica nas escolas condizentes com a prática tecnológica a ser adotada, para organizar os materiais didáticos planejados em conjunto com Projeto Político Pedagógico no ambiente virtual. Com a implantação de AVAs livres, permite que professores já capacitados consigam dar um passo adiante e utilizá-los como recurso híbrido dando um imenso apoio na sala de aula presencial. Proporciona autonomia aos educandos e parceria com todos os envolvidos.

Haja vista que esta investigativa não se esgota nestas poucas linhas e com uma futura continuação deste documento pode-se dizer que ao inserir uma plataforma AVA na instituição, em conjunto com a equipe pedagógica, é necessário haver uma equipe formativa com profissionais especialistas em tecnologias educacionais para dar suporte aos professores no uso e acolhimento das novas tendências que surgirão, para assim garantir a sua formação contínua. Este trabalho é indicado para docentes das redes públicas e privadas, para estudantes e para pesquisadores da área das tecnologias educacionais.

\section{REFERÊNCIAS}

BARBOZA, Esdras Jorge Santos; SALES FILHO, Antônio Gomes; SILVA, Marcia Terra da. Comparação entre os principais Ava's quanto a Interatividade. In.: XIV International Conference On 
AMBIENTES VIRTUAIS DE APRENDIZAGEM: LIMITES E POSSIBILIDADES PARA UTILIZACÃ̃O NO ENSINO MÉDIO Claudinete de Jesus da Silva

Engineering And Technology Education, 2016, Salvador. [Anais...] XIV International Conference on Engineering and Technology Education. Salvador: Uneb, 2016. p. 96-100. Disponível em: https://copec.eu/congresses/intertech2016/docs/BAINTERTECH2016C.pdf. Acesso em: 07 mar. 2020.

BARROS, D. M. V. Estilos de Aprendizagem e Tecnologias In.: RAMAL, A.; SANTOS, E. (Org.) Mídias e tecnologias na educação presencial e a distância. Rio de Janeiro: LTC, 2016, p. 233241 - ISBN 978-85-216-2656-5.

BASTOS, V. C. A aprendizagem do software scratch como atividade colaborativa na formação continuada de professores. Dissertação (Mestrado em Ensino e Educação Básica) - Instituto de Aplicação Fernando Rodrigues da Silveira, Universidade do Estado do Rio de Janeiro, Rio de Janeiro, 2016.

BRASIL. Lei n 9.394, de 20 de dezembro de 1996. Brasília: Diário Oficial da União, 23 dez. 1996.

Conselho Nacional de Educação. Define as Diretrizes Curriculares Nacionais para a formação inicial em nível superior (cursos de licenciatura, cursos de formação) e para formação continuada. Resolução CNE/CP ํํ. 02/2015, de $1^{\circ}$ de julho de 2015. Brasília, Diário Oficial da República Federativa do Brasil, seção 1, no. 124, p. 8-12, 02 de julho de 2015. Disponível em:

http://pesquisa.in.gov.br/imprensa/isp/visualiza/index.isp?data=02/07/2015\&jornal=1\&pagina=8\&total Arquivos=72. Acesso em 10 mar. 2020.

2005.

Decreto no 5.622, de 19 de dezembro de 2005. Brasília: Diário Oficial da União, 20 dez.

DIAS, Trindade S.; MOREIRA, J. A. Avaliação das competências e fluência digitais de professores no ensino público médio e fundamental em Portugal. Revista Diálogo Educacional, v. 18, n. 58, p. 624644, jul./set. 2018.

FRANCK, Adriana; NICHELE, Bruna. Mediação da Aprendizagem. In.: XII CONGRESSO NACIONAL DE EDUCAÇÃO, 2015, Curitiba. Anais do XIl Congresso Nacional de Educação. Curitiba: Editora Universitária Champagnat, 11 2015. p. 24080-24093. Disponível em: http://educere.bruc.com.br/arquivo/pdf2015/21225 10079.pdf. Acesso em: 08 jul. 2019.

FOFONCA, Eduardo; SCHONINGER, Raquel Regina Zmorzenski Valduga; COSTA, Carmen Sílvia da. A Mediação Tecnológica e Pedagógica em Ambientes Virtuais de Aprendizagem: contribuições da Educomunicação. Revista Tempos e Espaços em Educação, São Cristóvão, Sergipe, v. 11, n. 24, p. 267-278, jan./mar. 2018. Disponível em: https://seer.ufs.br/index.php/revtee/article/view/6031. Acesso em: 28 fev. 2020.

FONTOURA, Juliana; TRUJILLO, Diego. RIBEIRO, Rafael. Quais os desafios dos professores para incorporar as novas tecnologias no ensino? Revista e Educação, n. 249, 2018. Disponível em: http://revistaeducacao.com.br. Acesso em: 25 fev. 2020.

HORN, M. B.; STAKER, H. Blended: usando a inovação disruptiva para aprimorar a educação. Porto Alegre: Penso, 2015. 292 p.

LAKATOS, Eva Maria; MARCONI Marina de Andrade. Fundamentos de Metodologia científica. 5. ed. São Paulo: Atlas, 2003.

MARTINS, Gilberto de Andrade; THEÓPHILO, Carlos Renato. Metodologia da investigação científica para ciências sociais aplicadas. 3. ed. São Paulo: Atlas, 2016. 


\section{RECIMA21 - REVISTA CIENTÍFICA MULTIDISCIPLINAR}

AMBIENTES VIRTUAIS DE APRENDIZAGEM: LIMITES E POSSIBILIDADES PARA UTILIZAÇÃO NO ENSINO MÉDIO Claudinete de Jesus da Silva

MERCADO, L. P. Leopoldo. (Org.). Novas tecnologias na educação: reflexões sobre a prática. Maceió: Edufal, 2002.

MILLIGAN, C. Delivering Staff and Professional Development Using Virtual Learning Environments. In.: The Role of Virtual Learning Environments in the Online Delivery of Staff Development. Institute for Computer Based Learning, Heriot-Watt University, Riccarton, Edinburgh EH14-4AS. October 1999.

MOREIRA, António J.; BARROS, D.; MONTEIRO, A. Inovação e Formação na Sociedade Digital: Ambientes Virtuais, Tecnologias e Serius Games. Santo Tirso: White Books, 2015.

OKADA, A.; MIKROYANNIDIS, A.; MEISTER, I.; LITTLE, S. (2012). Coaprendizagem através de REA e Redes Sociais. In.: Okada, A. Análise do uso dos recursos tecnológicos como metodologia no ensino-aprendizagem. Educação, v. 39, n. 23, p. 5, 2018.

ROCHA, José D. T. NOGUEIRA, Clerislene. R. M. SANTOS, José L. SOUSA, Graciene R. Práticas Pedagógicas Curriculares. Uso das tecnologias na contemporaneidade. Revista Observatório, v. 4, n. 5, ago. 2018.

RUDIO, F. V. Introdução ao projeto de pesquisa científica. Petrópolis: Vozes, 2006.

SILVA, Flauviana Ramos da; CAMPOS, Valdenice Cavalcante. O Ensino a Distancia ao Longo das Gerações EaD. Compartilhando Saberes. Revista Digital da Secretaria de Educação, v. 1, n. 4, dez. 2016. Disponível em: http://www.sec.pb.gov.br/revista/index.php/. Acesso em: 06 mar. 2020.

TIC Educação 2016. Centro Regional de Estudos para o Desenvolvimento da Sociedade da Informação. (Cetic.Br). Revista e Educação, 2018. Disponível em: http://revistaeducacao.com.br. Acesso em: 25 fev. 2020.

UNESCO/COL. «Guidelines for open educational resources (OER) in higher education» 2011. Disponível em: https://link.springer.com/article/10.1007/s10499-019-00355-9. Acesso em: 08 mar. 2020.

VALENTE, J. A. Diferentes usos do computador na educação. Em Aberto, Brasília, v. 12, n. 57, p.1$14,1993$.

VERGARA, Sylvia Constant. Projetos e Relatórios de Pesquisa em Administração. 2. ed. São Paulo: Atlas, 1998.

VILLELA, Ana Paula; MESQUITA, Vania dos Santos. Educação a Distância: História no Brasil. CIET: EnPED, [S.I.], maio 2018. Disponível http://cietenped.ufscar.br/submissao/index.php/2018/article/view/49. Acesso em: 02 mar. 2020. 